\title{
The Public Health Sector and Nutrition in Cuba
}

\section{By Raúl Pérez, MD, MPH}

In Cuba, the responsibility for food and nutrition security is shouldered first and foremost by government. That is, government is obligated to develop and implement policies towards ensuring that the entire population has consistent access to safe and nutritious foods in sufficient quantities to satisfy daily nutritional requirements and food preferences, contributing to an active and healthy life. This is a tall order under any circumstances. But for Cuba, a small island nation with a GDP of US\$46 billion (2008), measuring up is tougher still, especially in the historical and international contexts.

Since the 1960s, a number of food staples have been sold in limited quantities to all Cuban families at governmentsubsidized prices. This and other measures to supplement nutrition for vulnerable groups prevented widespread hunger during the 1990s, when socialist Europe's collapse and more stringent US trade sanctions on Cuba caused severe economic and social hardship. Nevertheless, during that "Special Period", per capita daily energy intake decreased to 1863 kcal,[1] and micronutrient deficiencies were associated with a neuropathy epidemic affecting 50,000 people between 1992 and 1993.[2,3]

Since then, the economy has entered a recovery period. However, food production and imports today do not satisfy national demands, especially the diversity of offerings needed for a healthy diet. The reasons are multiple and not entirely the focus of this article. But suffice to mention a few of the most important: between October 2006 and October 2008, the Food and Agriculture Organization (FAO) Price Index rose 28\%, a blow dealt hardest to developing countries like Cuba.[4] The same year, three major hurricanes and the US embargo negatively impacted both agricultural production-for domestic consumption and exportand hard currency available for purchase by Cuba of foodstuffs abroad.[5,6]

Complicating this picture are domestic trends and policies. For example, as a result of internal emigration patterns over the years, $75 \%$ of all Cubans live in urban areas and are primarily food purchasers rather than producers.[7] This puts more pressure on an already depleted farming workforce. Recent broad reforms in agricultural, land use and marketing policies are aimed at correcting insufficient, overpriced and inconsistent supplies of fruits and vegetables in Cuban towns and cities, and at increasing domestically-produced foodstuffs to substitute for costly imports.[8]

From this brief outline, it is obvious that only a multi-sector approach can hope to successfully overcome the obstacles to achieving sound nutrition and food security. Such an approach is, in fact, the basis of recommendations put forward by the World Health Organization and the UN's Standing Committee on Nutrition.[9] In this context, the health sector-the Ministry of Public Health, its institutions and professionals-plays a leading role in several areas, including assessing the nutrition-related health problems that merit priority attention.
The three most pressing issues thus identified are unhealthy eating habits, iron-deficiency anemia in specific population groups, and increasing overweight and obesity in the population at-large. In each case, health sector experts have led multi-sector commissions to develop the national programs now in place to tackle these problems.

\section{National Nutrition Priorities \& Programs}

Unhealthy eating habits are a fact of life in Cuba, and can be summarized as follows:

- Inadequate distribution of energy intake throughout the day

- More animal-origin than vegetable-origin fats

- Low fish consumption

- Few fruits and vegetables

- Low whole-grain cereal consumption

- High sugar intake

- Preference for fried foods

- Underestimation of the risk presented by overweight and obesity

In addition to making healthier foods more readily accessible, such habits challenge us to change the mentality and behavior of millions of Cubans through systematic education and communication initiatives.

Two important tools have been developed as yardsticks for a national program to improve our food culture: the Dietary Reference Intakes (DRIs) for the Cuban Population (see Dietary Reference Intakes for the Cuban Population, 2008 this issue), outlining the nutrients necessary for an adequate Cuban diet, intended for use primarily by health professionals, policymakers and the food industry; and, based on this document, the Healthy Diet Guide, a nine-point plan for healthier eating designed for health professionals, the media, community organizations and the general public (see Cuba Teams Up for Better Nutrition this issue). The Guide was developed also mindful of diet's association with the main illnesses affecting the population (heart disease, cancer and stroke), availability and accessibility of various foods, the results of national studies on tastes and preferences, and other socio-cultural aspects that influence eating habits.

The Healthy Diet Guide has been distributed throughout the primary health care system and the networks of domestic trade, agriculture and food industry; used in coursework for nutritionists, other public health workers and teachers; and has been made available through the Virtual Health Library and the mass media, among other outlets. The Guide includes not only what foods are healthiest and in what combinations, but also recommends best modes of storage and preparation, timing of meals, and ideal weight.

This Guide is also the basis for the following main goals set forth for the year 2015:[10]

- Increase to $40 \%$ the percentage of the Cuban population eating at least 2 servings of fruit daily, $\sim 200 \mathrm{~g}$ (from baseline of $16 \%$ in 2001). 
- Increase to $50 \%$ the percentage of the Cuban population eating at least 3 servings of vegetables daily, $\sim 300 \mathrm{~g}$ (from baseline of $17 \%$ in 2001).

- Increase to $45 \%$ the percentage of Cubans aged $>2$ years whose fat intake constitutes $20-30 \%$ of total calories (from baseline of $19 \%$ in 2001).

- Increase to $55 \%$ the percentage of Cubans whose sugar consumption is $<15 \%$ of total calories (from baseline of $32 \%$ in 2001).

- Increase to $95 \%$ the percentage of Cubans who do not add salt to their meals at the table (from baseline of $88 \%$ in 2001).

Iron deficiency is the greatest micronutrient deficit present in Cuba. The population groups most affected are small children and reproductive-age women: currently, iron-deficiency anemia is found in $30-45 \%$ of infants aged 6 to 23 months, $25-35 \%$ of reproductive-age women, and $24 \%$ of pregnant women in their third trimester. While mild levels of anemia predominate in all these groups, the percentages are of concern as is the regional distribution, with the eastern provinces exhibiting the highest rates.

The multifaceted program developed to address iron-deficiency anemia includes the Ministry of the Food Industry, Ministry of Agriculture, Ministry of Domestic Trade, and the Ministry of Foreign Trade and Investment. We are working primarily to provide fortified foods and iron supplements, as well as to increase accessibility of iron-rich foods at the local level, especially for these population groups. In August 2009, the United Nations' system approved a grant of US\$8.5 million to assist in this effort over the next 3 years in 20 of the country's most vulnerable municipalities in the five eastern provinces and Pinar del Río province in the west. The project, with UNICEF as lead agency, also contemplates reinforcing our Food and Nutritional Surveillance System (SISVAN, its Spanish acronym).[11]

A key focal point for this program and the UN project is the network of municipal-level maternity homes established for all women identified with high-risk pregnancies, including those who have insufficient weight gain and iron-deficiency anemia. The program also reinforces initiatives to increase the percentage of women who exclusively breastfeed their infants through the first six months of life (26\% in 2006).[12]

By 2015, the program's national goals are to reduce irondeficiency anemia to:

- $15 \%$ in children aged <2 years (from a 2003 baseline of $30 \%$ with $\mathrm{Hb}<110 \mathrm{~g} / \mathrm{L})$

- $19 \%$ in reproductive-age women (from a 2003 baseline of $30 \%$ with $\mathrm{Hb}<120 \mathrm{~g} / \mathrm{L}$ )

- $15 \%$ in pregnant women (from a 2004 baseline of $24 \%$ with $\mathrm{Hb}<110 \mathrm{~g} / \mathrm{L})$

Related nutritional goals for 2015 include:

- Reduce to $8 \%$ the percentage of pregnant women with insufficient weight gain (from baseline of $16.9 \%$ in 2001).

- Reduce to $3.5 \%$ the percentage of children aged $<5$ years with stunted growth (from baseline of $5.7 \%$ in 2001). [10]

Overweight and obesity constitute growing health problems in Cuba, especially given their association with noncommunicable chronic diseases (see Overweight, Obesity, Central Adiposity and Associated Chronic Diseases in Cuban Adults this issue).

As in most middle-income countries, over the last few decades, Cuba's population has experienced a shift in diet toward more processed, higher energy fare along with diminished regular physical activity. This, combined with other factors mentioned above, has led to additional pounds: in $1995,32.0 \%$ of Cuba's adult population was overweight, and by $2001,42.6 \%$. More adult Cuban women tend be overweight than men (46.9\% in 2001 compared to $37.6 \%$ in 1995); and nearly twice as many women are obese $(15.4 \%$ compared to $7.9 \%$ ). In addition, $45 \%$ of those overweight and obese accumulated excess abdominal fat, making them yet more prone to various chronic conditions.[13]

The national program to reduce overweight and obesity is also a multi-sector effort, based on public education using the Healthy Diet Guide and encouraging physical activity and exercise, as well as medical orientation for individuals with excess weight. A major challenge is to bring selection of food imports, production and distribution into line with the Guide.

For the year 2015, the goals are:[10]

- Increase to $65 \%$ the percentage of Cuban adult men and to $56 \%$ the percentage of Cuban adult women who are within normal weight range, expressed as a body mass in$\operatorname{dex}(\mathrm{BMI})$ of $18.5-24.9$ (from baseline of $57 \%$ and $46 \%$, respectively).

- Reduce to $4 \%$ the percentage of Cuban adult men and to $10 \%$ the percentage of Cuban adult women who are obese, expressed as a BMI of $\geq 30$ (from baseline of $8 \%$ and $15 \%$, respectively).

\section{Health Sector Expertise at the Service of Nutrition}

To support the programs outlined above, the health system, its institutions and professionals are responsible for a spectrum of supporting activities, as follows:

\section{- Clinical Services and Human Resources Development}

Gradually, Cuba's nearly 500 community-based polyclinics are being reinforced with the addition of a nutritionist, whose multifaceted role is to offer nutrition counseling services to individuals and families, paying particular attention to vulnerable groups (including infants and young children, pregnant and lactating women, HIVIAIDS patients, and those with chronic conditions); assess the quality of diet offered at schools, childcare centers, maternity homes, nursing homes and hospitals in the geographic catchment area served by the polyclinic; and work with community organizations to promote healthy eating and exercise in the local population, based on the Healthy Diet Guide.

Currently, some 3000 nutritionists are in training at university level; 154 other health professionals have earned master's degrees in nutrition; and nutritionists have already been assigned to $80 \%$ of the country's polyclinics.

\section{- Food Safety Control}

Hygiene, Epidemiology, and Microbiology Units and their laboratories at the municipal and provincial level are responsible for 
food safety. They also provide technical training for the teams of inspectors they supervise. At the national level, a National Food Registry provides the guidelines for inspection and for approval of each foodstuff produced or imported.

\section{- Nutritional Surveillance}

One of the most important responsibilities of the public health sector, carried out by the Nutrition and Food Hygiene Institute (INHA, its Spanish acronym), is nutritional surveillance to provide consistent and reliable data to alert health authorities of any nutritional crisis, provide epidemiological evidence of dietary and nutritional trends, and measure the impact of national programs to improve nutritional status.

The Food and Nutritional Surveillance System, SISVAN, monitors seven different aspects:

- Food availability: tracks national distribution trends of food staples compared to established DRIs.

- Food accessibility: measures real accessibility of agricultural and other foods, following a variety of products offered and their prices. - Institutional diets: assesses indicators of supply and per capita consumption of foods, calories and selected nutrients in childcare centers, schools and workplace cafeterias.

- Mother-child nutrition: through sentinel sites, facilitates anthropometric and biochemical data on the nutritional state of pregnant women and children under 5 years old.

- Health institution diets: offers data on diet and nutritional status of persons in hospitals, maternity homes and other health institutions, in reference to adequate intake of energy, protein and fats.

- Nutrition program impact: identifies gaps and failures to meet targeted goals-from production through food consumptionthrough structural, process and impact indicators. Includes supplementary diet and enriched food programs.

- Utilization of iodized salt: oversees these levels to ensure Cuba maintains its status as a country free from iodine-related deficiencies and disorders.

\section{- Continued Research}

The health system is devoting considerable resources to continue research into nutrition, diet and physical activity and their interaction with each other and with associated diseases and risk factors. Most recently, a national research group coordinated by the $\mathrm{Na}-$ tional Hygiene, Epidemiology and Microbiology Institute (INHEM, its acronym in Spanish) has already begun the third national survey on risk factors and noncommunicable chronic diseases, which will give us vital fresh data for comparison.

\section{Advances and Challenges Ahead}

Some $60 \%$ of all deaths globally are due to noncommunicable chronic diseases (NCDs), mainly cardiovascular diseases, diabetes, cancers and chronic respiratory diseases, and $80 \%$ of deaths from these conditions are in the developing world. In 2008, WHO predicted that overall deaths from NCDs would increase another $17 \%$ over the next decade.[14]

In this context, WHO's Action Plan for the Global Strategy for the Prevention and Control of NCDs for 2008-2013 called on member governments to develop a multi-sector framework to address these diseases, their prevention and control. Specifically, the plan called for states, among other things, to develop national policies and action plans on food and nutrition, promote exclusive breastfeeding for the first six months of life, promote programs to ensure optimal feeding for all infants and young children, establish and implement dietary guidelines, support healthier composition of foods, and provide accurate information for consumers.[14]

Cuba's evidence base, its national framework, plans and programs are in place, and undoubtedly one of the country's strengths lies in its universal health care system. Nevertheless, the economic and social environment for achieving healthy nutrition is not entirely a favorable one, and it will take more profound and concerted interaction among all sectors in the country, and a greater attention to child and adolescent nutrition in particular, to make the necessary changes and sustain them over time. -1 -

\section{References \& Notes}

1. Franco $M$, Orduñez $P$, Caballero $B$, Cooper RS. Obesity reduction and its possible consequences: What can we learn from Cuba's Special Period? CMAJ. 2008 Apr 8;178(8):1032-4

2. The Cuba Neuropathy Field Investigation Team. Epidemic optic neuropathy in Cuba: Clinical characterization and risk factors. N Engl J Med. 1995 Nov 2;333(17):1176-82.

3. Almiral P, Antelo J, editors. In: Neuropatía Epidémica en Cuba, 1992-1994. Havana: Centro Nacional de Información de Ciencias Médicas; 1995.

4. The State of Food Insecurity in the World 2008. Rome: United Nations Food and Agriculture Organization; 2008.

5. Cuban Ministry of Foreign Affairs [Internet]. Havana: Informe de Cuba sobre la resolución 63/7 de la Asamblea General de las Naciones Unidas; [updated 2009; cited 2009 Oct 2]. Available from: http://www.cubavsbloqueo.cu/lnforme2009/Informelngles/indexing.html

6. Información oficial de datos preliminares sobre los daños ocasionados por los huracanes Gustav e Ike. Granma. 2008 Sep 16. Available from: http://www. granma.cubaweb.cu/2008/09/16/nacional/artic03.html

7. Población media según grupos de edades, sexos y zonas, año 2007. In: Anuario Estadístico de Cuba 2007. Edición 2008 [Internet]; Havana: National Statistics Bureau (CU); [updated 2008; cited 2009 Oct 9]. Available from: http:// www.one.cu/aec2007/datos/III.3.xls

8. Decreto-Ley No.259 sobre la entrega de tierras ociosas en usufructo. Granma. 2008 Jul 18. Available from: http://www.granma.cubaweb.cu/2008/07/18/ nacional/artic05.html. See also: Debaten deficiencias y reformas para agromercados. Granma. 2009 Oct 5. Available from http://www.granma.cubaweb. cu/2009/10/04/nacional/artic19.html

9. United Nations System Standing Committee on Nutrition. Fifth Report on the World Nutrition Situation: Nutrition for Improved Development Outcomes 2004. Geneva: United Nations Organization; 2004.

10. Ministry of Public Health (CU). Proyecciones de la salud pública en Cuba para el 2015. Havana: Editorial de Ciencias Médicas; 2006.

11. See MDGF-2037: Support for the fight against anemia in vulnerable groups in Cuba. Concept note for original application. MDG Achievement Fund, UNDP, Havana; 2006. See also Aprobado programa conjunto "Apoyo a la lucha contra la anemia en grupos vulnerable en Cuba", 15 Aug 2009, UNDP, Havana (press release).

12. United Nations Children's Fund. Child Nutrition: Infant and young child feeding (2000-2007) [monograph on the Internet]. New York: United Nations Children's Fund; 2009 Jan [cited 2009 Oct 2]. Available from: http://www.childinfo.org/ breastfeeding_countrydata.php.

13. National Hygiene, Epidemiology and Microbiology Institute (CU). Primera y Segunda Encuesta Nacional de Factores de Riesgo de Enfermedades no Transmisibles en Cuba. Informe de trabajo. Havana; 2002.

14. World Health Organization. Action Plan for the Global Strategy for the Prevention and Control of NCDs 2008-2013. Geneva: WHO; 2008. 